
BASED PLASTIC-BONDED EXPLOSIVES

RAYMOND L. FLESNER, DX-2

PHILIP C. DELL'ORCO, DX-2

TERRY SPONTARELLI, DX-2

ROBERT L. BISHOP, DX-2

CARY SKIDMORE, DX-2

KENNETH J. UHER, DX-2,

JOHN F. KRAMER, DX-2
5

JUL 191936

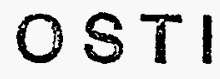

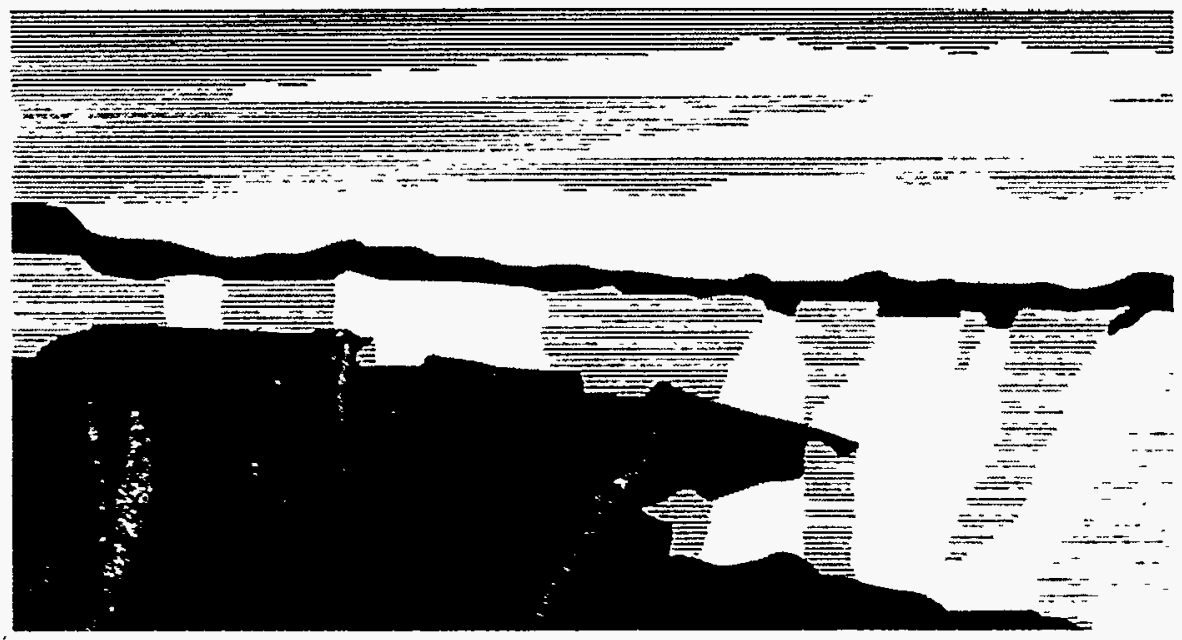

Los Alamos Natlonal Laboratory, an atilimative actionlequal oportunity emobyer, Is operated by the University of California for the US. Department of energy under contract W-7405-ENG-36. By acceptance of this article, the publisher recognizes that the U.S. Govemment retains a nonexclusive, royalty-free license lo publish or reproduce the published form of this contribution, or to allow others to do so, for U.S. Govemment purposes. The Los Alamos National Laboralory requests that the pubitsher identity this article as work pertormed under the auspices of the U.S. Department of Energy. 


\section{DISCLAIMER}

This report was prepared as an account of work sponsored by an agency of the United States Government. Neither the United States Government nor any agency thereof, nor any of their employees, makes any warranty, express or implied, or assumes any legal liability or responsibility for the accuracy, completeness, or usefulness of any information, apparatus, product, or process disclosed, or represents that its use would not infringe privately owned rights. Reference herein to any specific commercial product, process, or service by trade name, trademark, manufacturer, or otherwise does not necessarily constitute or imply its endorsement, recommendation, or favoring by the United States Government or any agency thereof. The views and opinions of authors expressed herein do not necessarily state or reflect those of the United States Government or any agency thereof. 


\title{
Pilot-Scale Base Hydrolysis Processing of HMX-Based Plastic-Bonded Explosives
}

R.L. Flesner, P.C. Dell'Orco, T. Spontarelli, R.L. Bishop, C.B. Skidmore, K. Uher, and J.F. Kramer, Explosives Technology and Safety, Los Alamos National Laboratory, Los Alamos, NM 87545

\begin{abstract}
Los Alamos National Laboratory has demonstrated that many energetic materials can be rendered non-energetic via reaction with sodium hydroxide or ammonia. This process is known as base hydrolysis. A pilot scale reactor has been developed to process up to $20 \mathrm{~kg}$ of plastic bonded explosive in a single batch operation. In this report, we discuss the design and operation of the pilot scale reactor for the processing of PBX 9404, a standard Department of Energy plastic bonded explosive containing HMX and nitrocellulose. Products from base hydrolysis, although non-energetic, still require additional processing before release to the environment. Decomposition products, destruction efficiencies, and rates of reaction for base hydrolysis will be presented. Hydrothermal processing, previously known as supercritical water oxidation, has been proposed for converting organic products from hydrolysis to carbon dioxide, nitrogen, and nitrous oxide. Base hydrolysis in combination with hydrothermal processing may yield a viable alternative to open burning/open detonation for destruction of many energetic materials.
\end{abstract}

\section{Introduction}

\section{Bench and Pilot-Scale Base Hydrolysis of HMX Based Explosives}

The safe disposal of excess high explosives has become increasingly important in recent years due to the disassembly of large quantities of Cold War munitions. Thus far, the primary disposition of waste high explosives has been open burning/open detonation (OB/OD). Due to noise concerns and the dispersion of undesirable burning products, $\mathrm{OB} / \mathrm{OD}$ has recently fallen out of favor with state and federal regulatory agencies. This has prompted the development of safe and environmentally benign disposal alternatives. One high explosive disposal alternative being developed in parallel by industry and Los Alamos National Laboratory is base hydrolysis.

Base hydrolysis is a process whereby explosives are reacted with concentrated base solutions $(1-8 \mathrm{M})$ at elevated temperatures $\left(80^{\circ} \mathrm{C}\right.$ to $\left.150^{\circ} \mathrm{C}\right)$ to produce non-energetic, water soluble reaction products. At temperatures above the normal solution boiling point, the process is carried out in pressurized reactors. Bases used include sodium hydroxide, potassium hydroxide, ammonium hydroxide, and sodium carbonate; although water is the most commonly used solvent, other solvents (i.e., ethanol, DMSO) may be used neat or in combination with water to reduce mass transfer resistances to reaction. Several different reaction paths occur in the hydrolysis process, including hydrolysis, oxidation/reduction, and substitution/elimination. These reaction paths produce a product stream which largely consists of simple carboxylic acids, amines, sodium salts, ammonia, and gaseous nitrogen/nitrous oxide. In general, hydrolysis reactions consist of parallel mass transfer and reaction kinetic steps; the temperature, pressure, and solvent combination determine whether mass transfer or reaction kinetics is the rate limiting step.

A variety of explosives has been successfully treated using base hydrolysis. ${ }^{1}$ Both nitramines and nitroaromatics are converted to water soluble, non-energetic products. When high volume loadings of base-resistant binders are present in a formulation, solvents 
generally have to be added to swell the binder, thus allowing base access to the high explosive. In addition to bulk explosives, base hydrolysis has also been shown to be effective in regenerating explosive-laden activated carbon, ${ }^{2}$ and in treating HE contaminated rags and soils.

Base hydrolysis has been successfully transitioned to large scale operations. Currently, two large-scale units are scheduled for implementation later this year at Eglin Air Force Base and the Pantex Plant in Amarillo, Texas An ammonia-based hydrolysis process is operational at Thiokol to treat CYH rocket propellant. ${ }^{3}$ In addition, Chemical Systems Division, a propellant manufacturer in northern California, is currently using base hydrolysis to destroy some of their waste energetic materials. ${ }^{4}$

The objective of this paper is to summarize research efforts in the base hydrolysis of HMX formulations at Los Alamos National Laboratory (LANL). Research at LANL has been primarily focused on PBX's from Department of Energy dismantlement programs. Specifically, we have focused on PBX 9404, a 94\% HMX composition. Both bench and pilot-scale studies have been conducted, with the purpose of developing a prototype reactor for use at the DOE's dismantlement plant at Amarillo, Texas. Atmospheric and pressurized hydrolysis processes have been evaluated in the laboratory. Results from the testing of a pilot-scale atmospheric hydrolysis reactor for PBX 9404 will be presented here. Ongoing work includes further investigation of mass transfer resistances as a function of temperature, pressure, and base composition, and the development of a pilot-scale pressurized hydrolysis reactor for use in DOE dismantlement activities.

\section{Experimental Methods}

A pilot-scale batch reactor was constructed for the purpose of hydrolyzing large explosive pieces into water soluble, non-explosive products. PBX 9404 (94\% HMX, 3\% nitrocellulose binder, $3 \%$ chloroethylphosphate plasticizer, and $0.1 \%$ diphenylamine (nitrocellulose stabilizer)) was used in this study. Two forms of explosive were studied: molding powder and consolidated charges. Molding powder consisted of small particles or pieces of plastic-covered explosive up to $0.5-1 \mathrm{~cm}$ in diameter. Consolidated pieces were manufactured by pressing molding powder in high pressure hydrostatic presses at elevated temperatures.

A stainless steel 55-gallon container was used as the basis of the reactor system. Two 7.5 KW Tempco electric circulation heaters (model \# CR3N-4008-4G 7.5) were used to heat the fluid $(\mathrm{NaOH}, 0.8-1 \mathrm{M})$ up to $90^{\circ} \mathrm{C}$. Hydrolysis liquor was circulated through the heaters using a Wilden M-1 stainless steel/Teflon air operated diaphragm pump (model \# $\mathrm{M} 1 / \mathrm{ST} / \mathrm{TF} / \mathrm{TF} / \mathrm{ST}$ ). Hydrolysis liquor was pumped from the bottom of the reactor, into the diaphragm pump, through the heaters, and then back into the sides of the reactor. A schematic of the initial reactor configuration is shown in Figure 1. The flow pattern and design of the reactor were later modified to alleviate solid accumulation problems, as discussed later.

An experiment was initiated by filling the reactor with a base solution. Either molding powder or a consolidated piece were placed in a stainless steel basket inside of the reactor. For the molding powder experiments, only one basket was used. For the first consolidated piece experiment, a cage was used to initially place the explosive inside the reactor. This cage rested on the bottom of the steel basket inside the reactor. In an attempt to increase the mass transfer in the reactor and therefore the overall reaction rate, the steel basket was not used in the second consolidated piece experiment. The steel cage merely rested on the bottom of the reactor immediately above an air sparge. 
Base Hydrolysis Batch Reactor Schematic, Initial Configuration

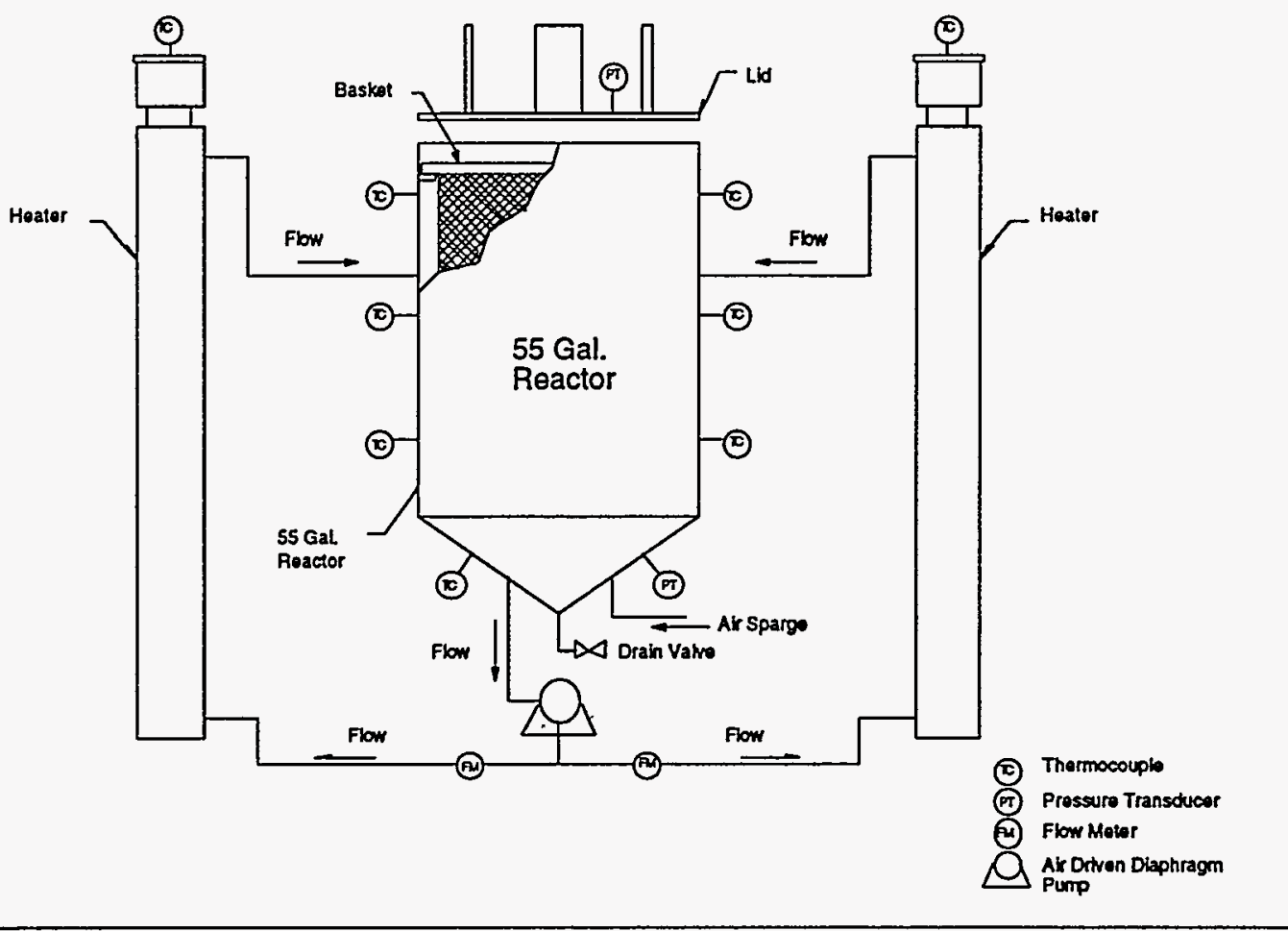

Figure 1. Base Hydrolysis Batch Reactor, Initial Configuration. This configuration was used only during the first 30 pound molding powder experiment.

Mixing in the reactor was accomplished by pump circulation and an air sparge. One inch stainless steel tubing and Swagelok fittings were used as plumbing between the reactor, pump, and circulation heaters. Paddlewheel flowmeters (Omega, model \#FP-5300) measured flow through either side of the reactor. Type $\mathrm{K}$ thermocouples were used to monitor temperature at various points in the reactor and in the heater's thermowells. Viatran pressure transducers (model 244) measured head pressure of the liquid inside the reactor.

The system was monitored remotely during experiments using a Stanford SR630 thermocouple monitor, an Apple Macintosh computer with a National Instruments GPIB board, and National Instruments LabVIEW software. Thermocouple, flow, and pressure measurements were all monitored at the computer, and this data was all logged to the hard drive as an ASCII file. In addition, the LabVIEW program controlled the temperature of the heaters via a PID control scheme that fed a 4-20ma current to 3 phase, 208V Omega solid state relays (SCR73Z-260 60). The control panel from the LabVIEW program is shown if Figure 2.

Liquid samples were analyzed by ion chromatography (IC) for anions and cations, total organic carbon (TOC) and total inorganic carbon (TIC), and by a $\mathrm{pH}$ meter. The IC anion analysis determined acetate, formate, nitrite, nitrate, oxalate, and glycolate. Cations measured were ammonia, sodium, and methylamine. 


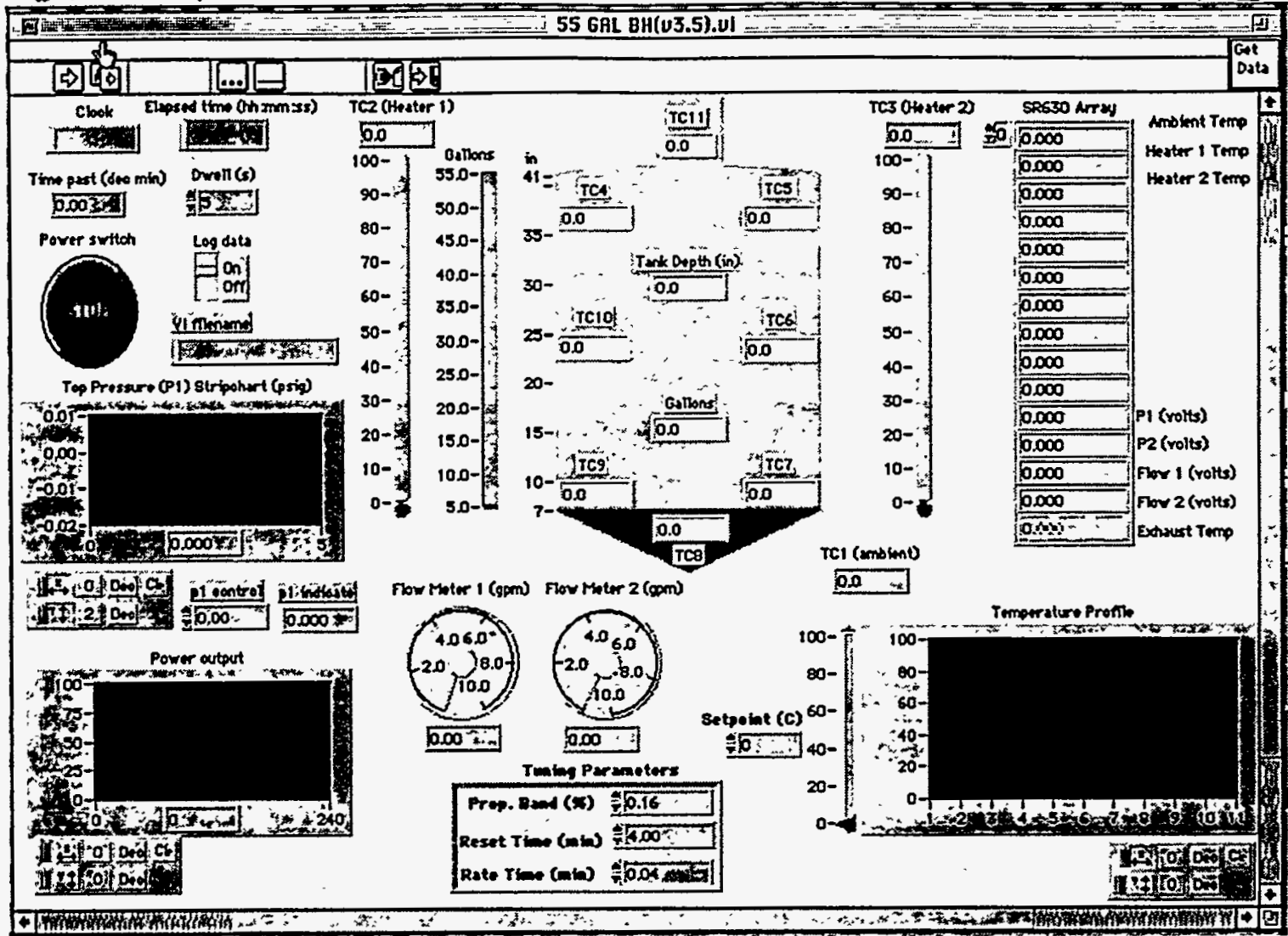

Figure 2. LabVIEW Control Panel for Computer Control of Pilot-Scale Base Hydrolysis

Unit. LabVIEW was run on an Apple Macintosh IIfx computer.

\section{Results and Discussion}

\section{Pilot-Scale Results}

\section{PBX 9404 molding powder}

Two experiments were performed using $30 \mathrm{lb}$ of molding powder. In the first experiment, significant solids accumulation occurred. This accumulation severely choked fluid flow through the heaters. In the original plumbing scheme (Figure 1), the powder was pumped from the bottom of the reactor, into the pump, and then through the external circulation heaters. The nitrocellulose in the powder reacts relatively fast (within minutes at $80^{\circ} \mathrm{C}$ ), ${ }^{5}$ and most of the HMX accumulated in the pumps and the plumbing near the bottom of the reactor. Within the first 40 minutes of operation, the reactor plugged. The bulk fluid temperature at the time of plugging was $68^{\circ} \mathrm{C}$. Although serious plugging occurred throughout the bottom of the reactor system, no serious exotherms were detected in any part of the reactor.

Because of the serious nature of the solids accumulation, the reactor was reconfigured so that fluid was pumped from the side of the reactor, into the diaphragm pump and to the heaters before being returned to the bottom of the reactor. The new pumping scheme is shown in Figure 3. The advantage of this pumping scheme is that HMX powder that has not yet reacted in the tank will not settle and plug the reaction pumping system and heaters. The disadvantage is that since the pump inlet is taking fluid from the sides of the reactor, a 
minimum amount of liquid must be maintained in the reactor for the system to work properly. This minimum amount is approximately 40 gallons.

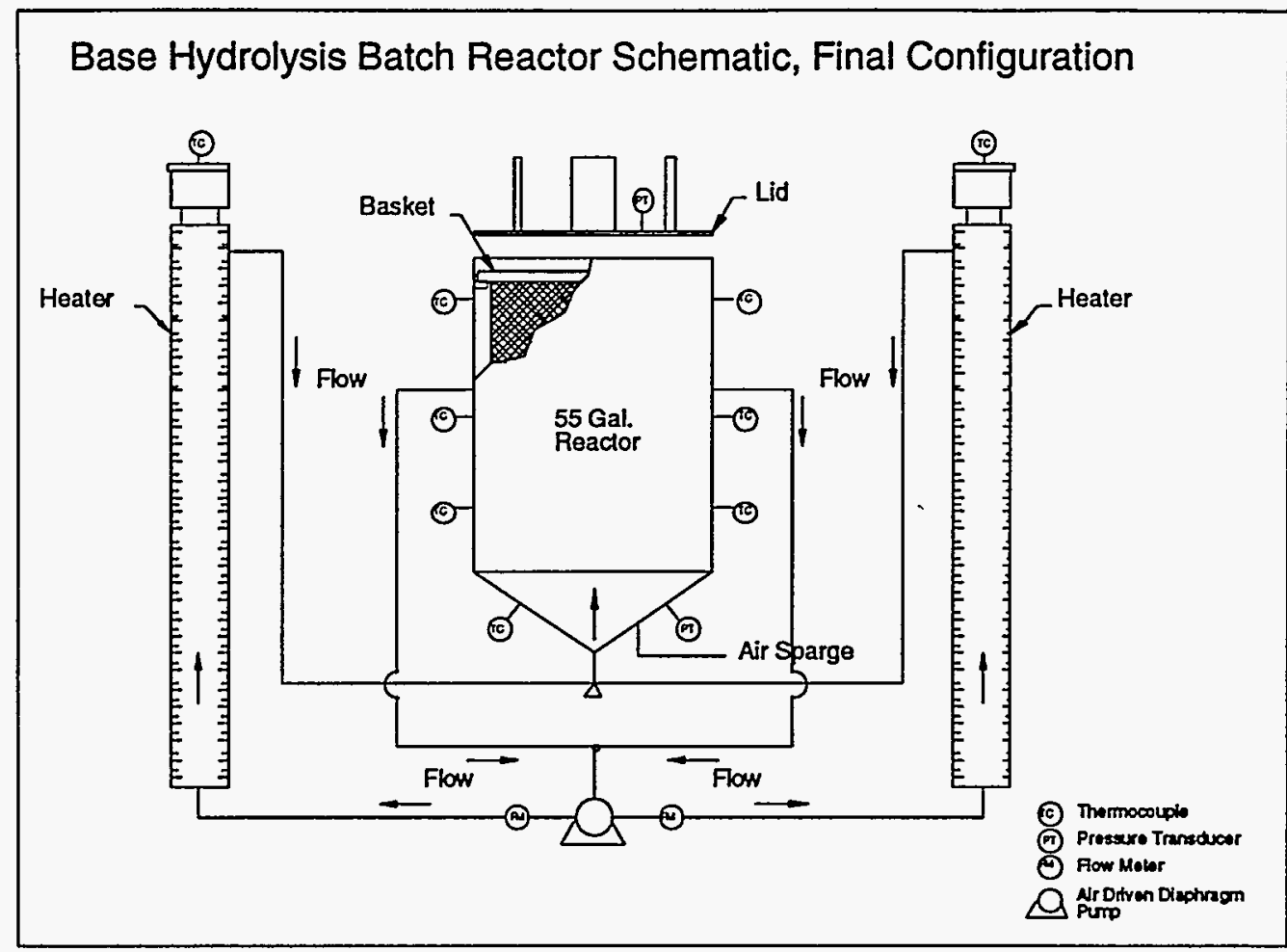

Figure 3. Base Hydrolysis Reactor Schematic, Final Configuration. This configuration was used after the reactor plugged significantly in the first molding powder experiment.

Another $30 \mathrm{lb}$ molding powder experiment was conducted with the configuration displayed in Figure 3. In this second molding powder experiment, the fluid was heated from $30^{\circ} \mathrm{C}$ to $85^{\circ} \mathrm{C}$ in approximately 1.6 hours. Similar to the first experiment, by the time the solution reached $85^{\circ} \mathrm{C}$, most of the nitrocellulose had reacted releasing the fine HMX powder. At this point, possible intermittent plugging was observed in one of the flow lines, which continued for about 70 minutes. Instead of plugging, the paddle of one of the flowmeters may have caught itself during this time on a plastic insertion fitting. The reaction timetemperature history is shown in Figure 4. In this figure, the heater temperature, the bulk fluid temperature, and the set point temperature are shown. Approximately 2 hours after the experiment began, one of two flow sensors indicated that intermittent plugging or flowmeter measurement problems were taking place. When this was observed, the heaters were completely tumed off. This is indicated by the abrupt change in temperature set point at approximately 3 hours time, (dashed line, Figure 4). After the heating power was turned off, a slight exotherm of approximately $4^{\circ} \mathrm{C}$ was also observed and is indicated on the graph. Most likely, some nitrocellulose continued to hydrolyze and caused the temperature increase.

\section{PBX 9404 consolidated pieces}

This reactor was originally designed to remediate large pressed pieces of PBX 9404, not molding powder. Much of the DOE's remediation mission is to get rid of large pressed pieces. These pieces require a longer reaction time since the system is mass transfer limited, which leads to less powder present at any one time, reducing the chance of plugging. Furthermore, the slower reaction rate will cause the exotherm created by the degradation of nitrocellulose to be much less. The molding powder experiments were 
judged to be a worst case reaction scenario for solids loading in the reactor. They were carried out to both illustrate the robust capabilities of the system, and to give the system a thorough safety test.

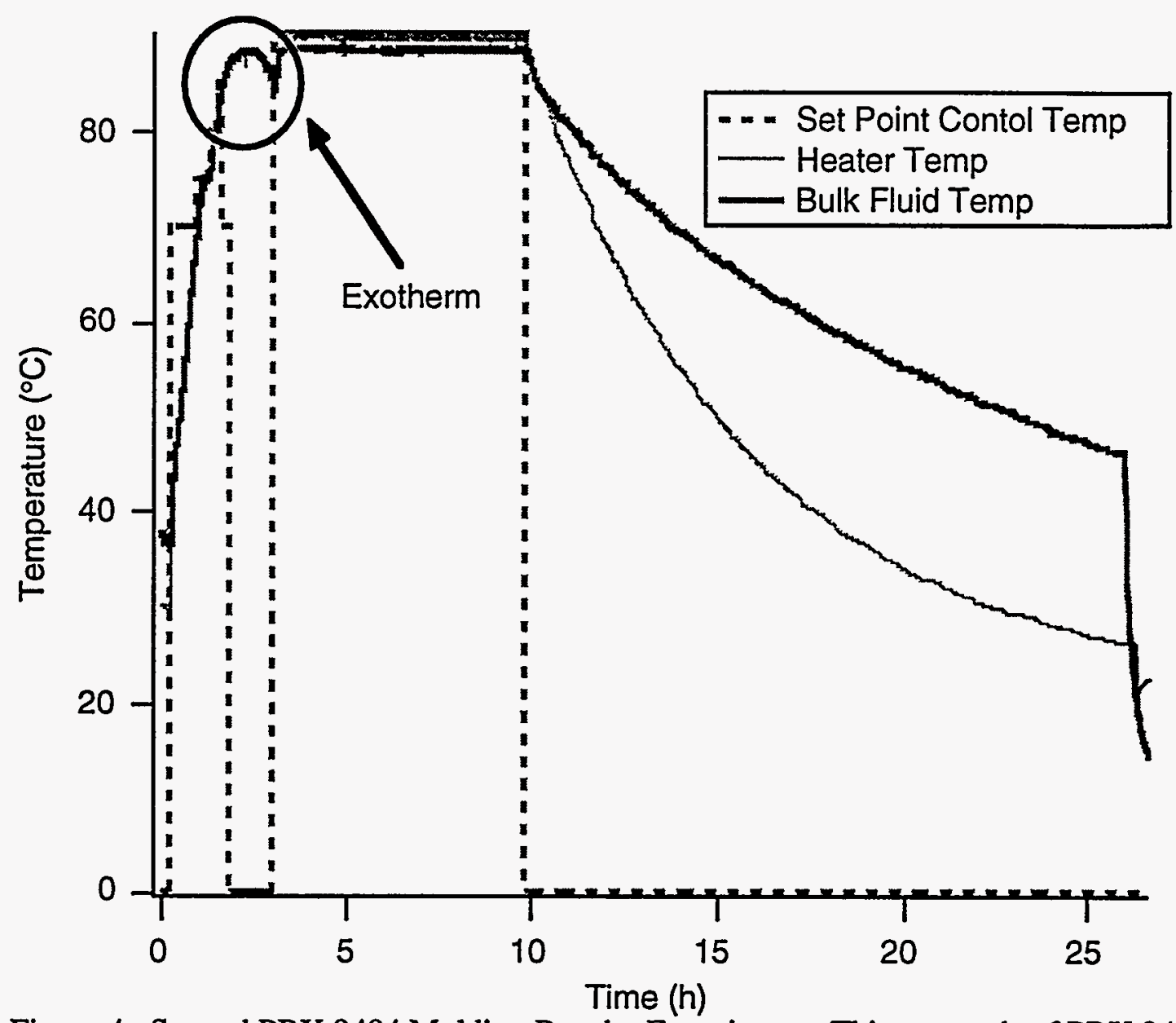

Figure 4. Second PBX 9404 Molding Powder Experiment. Thirty pounds of PBX 9404 molding powder were hydrolyzed in $45 \mathrm{gal}$ of $1.0 \mathrm{M} \mathrm{NaOH}$.

Consolidated pieces were hydrolyzed in two different experiments. Each experiment involved a single pressed $\mathrm{PBX} 9404$ piece made from molding powder. In the first experiment, a charge weighing less than $35 \mathrm{lb}$ was hydrolyzed in 45 gal of $1 \mathrm{M} \mathrm{NaOH}$. The fluid was initially heated to near $90^{\circ} \mathrm{C}$ and then held above $80^{\circ} \mathrm{C}$ for 9 hours. The reactor was allowed to cool overnight. The next morning, the basket was taken out of the reactor, and a significant quantity of the pressed piece remained. The piece was not weighed at this point, but was returned back to the reactor and heated again that day. The reactor was held above $80^{\circ} \mathrm{C}$ for an additional 8.7 hours. The reactor was then allowed to cool overnight. The time-temperature history of the reaction is shown in Figure 5. The following morning, a small piece was removed. The solution was then drained and filtered, and a small amount of additional HMX powder was recovered $(100-200 \mathrm{~g})$. The total amount left was $6 \%$ of the starting material. The rest of the explosive had been converted to base hydrolysis products (i.e., water soluble aqueous compounds, and $\mathrm{N}_{2}$, $\mathrm{N}_{2} \mathrm{O}$, and $\mathrm{NH}_{3}$ ).

In the second experiment, we attempted to increase the mixing and therefore the overall mass transfer of the solid explosive into the surrounding base solution. We achieved this 
by removing the basket that held the explosive as previously described in the Experimental Methods section. It was hoped that the additional mixing created by having the air sparge near the explosive would cause the explosive to hydrolyze faster. This was not necessarily the case. In the second experiment, we achieved approximately $87 \%$ destruction. This was less than the first experiment, where we achieved $94 \%$ destruction, however the reaction was not held at temperature as long. These results are summarized in Table 1.

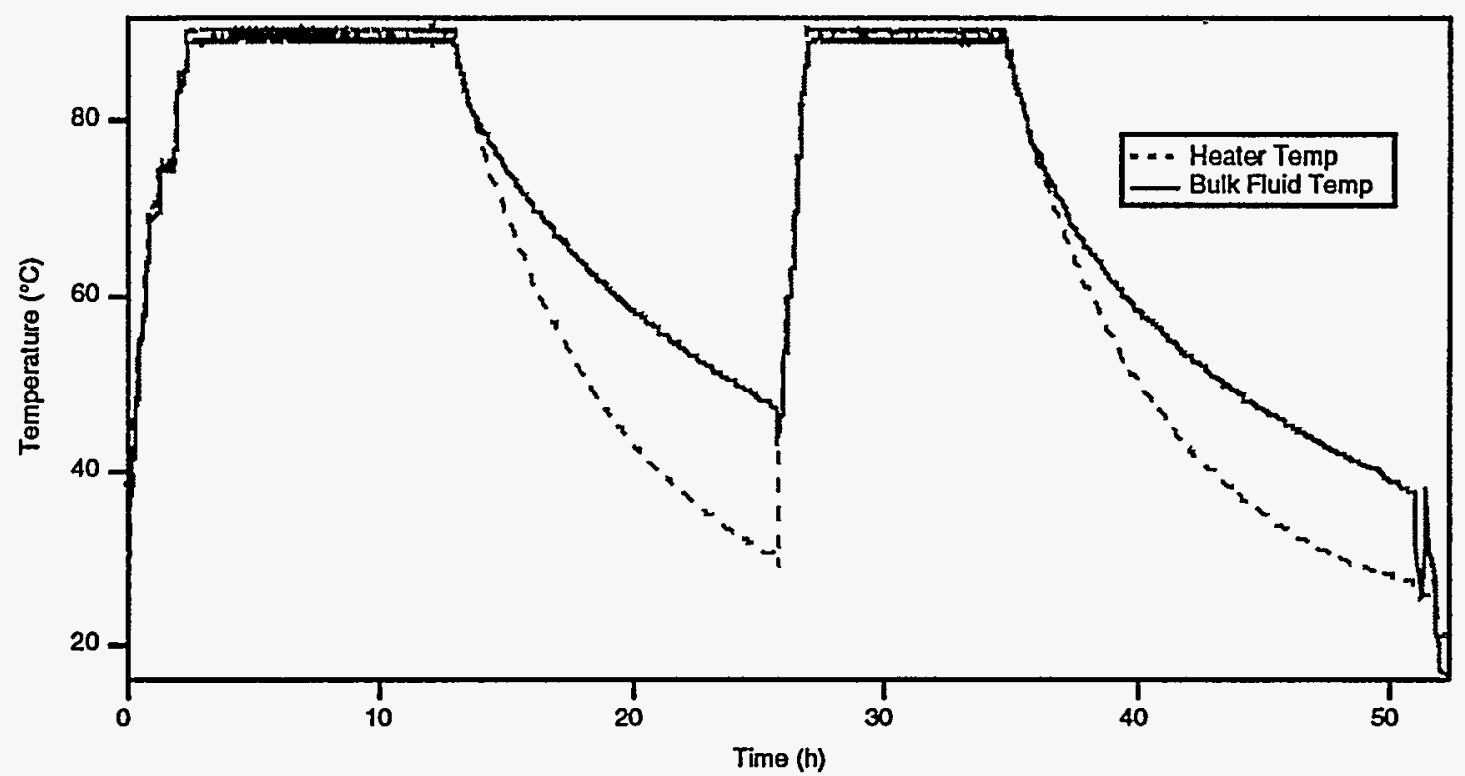

Figure 5. First PBX 9404 Consolidated Piece Experiment. One PBX 9404 pressed piece (weighing less than $35 \mathrm{lb}$ ) was hydrolyzed in $45 \mathrm{gal}$ of $1.0 \mathrm{M} \mathrm{NaOH}$.

\begin{tabular}{|lll|}
\hline \multicolumn{3}{|c|}{ Table 1. Destruction percentage of consolidated PBX 9404 High Explosive } \\
\hline Experiment Number & Time above $80^{\circ} \mathrm{C}(\mathrm{h})$ & High Explosive Destruction \% \\
\hline Consolidated Exp \#1 & 21 & 94 \\
Consolidated Exp \#2 & 18 & 87 \\
\hline
\end{tabular}

Both experiments proceeded at approximately the same rate. If the rate is assumed to be approximately linear for the whole reaction, the amount of explosive hydrolyzed per unit time in the second experiment is slightly more ( $4.9 \%$ reacted per hour vs. $4.6 \%$ for the first experiment). This assumption is not completely true; past experiments have shown that the reaction rate is not linear with time. The reaction slows somewhat as it proceeds, both due to the depletion of hydroxide ion as the reaction progresses and to the increased concentration of soluble salts in the liquid that tend to "salt out" organic species, thus reducing their solubility. Approximate reaction rates of the two consolidated pieces are reported in Figure 6 . Also shown in Figure 6 is the overall reaction rate of the second molding powder experiment and a comparison to experiments performed in a lab scale - reactor at 90 and $150^{\circ} \mathrm{C}$. In one of the lab-scale experiments (indicated by $150-\mathrm{P}$ on the $\mathrm{x}$ axis), a single consolidated piece (2" diameter by 3 " high cylinder) weighing a total of 284 $\mathrm{g}$ was used. In this experiment, the temperature was raised to $150^{\circ} \mathrm{C}$ for $53 \mathrm{~min}$. At the end of the experiment, $99.8 \%$ of the explosive had been destroyed.

Figure 6 shows a qualitative comparison in reaction rates between molding powder and consolidated pieces at both small and large scales. Since this is a mass transfer limited reaction, ${ }^{1}$ the available explosive surface area plays a large role in the rate. This is reflected in the faster reaction rate for molding powder compared to the consolidated pieces. The 
high temperature experiments are included to show the increase in mass transfer (even without stirring), and therefore the overall increase in reaction rate. A direct comparison of rates for consolidated pieces shows that destruction rates increase nearly 2 orders of magnitude when the temperature is increased from $90^{\circ} \mathrm{C}$ (mixed) to $150^{\circ} \mathrm{C}$ (with no mixing). We do not expect that reaction rates will scale linearly with respect to explosive size because of the general decrease in ratio of surface area to volume when larger consolidated pieces are used. Preliminary estimates indicate that a large scale charge may take from 2 to 4 times longer than the small scale piece treated at $150^{\circ} \mathrm{C}$. Mixing should also significantly increase mass transfer at the higher temperatures as well.

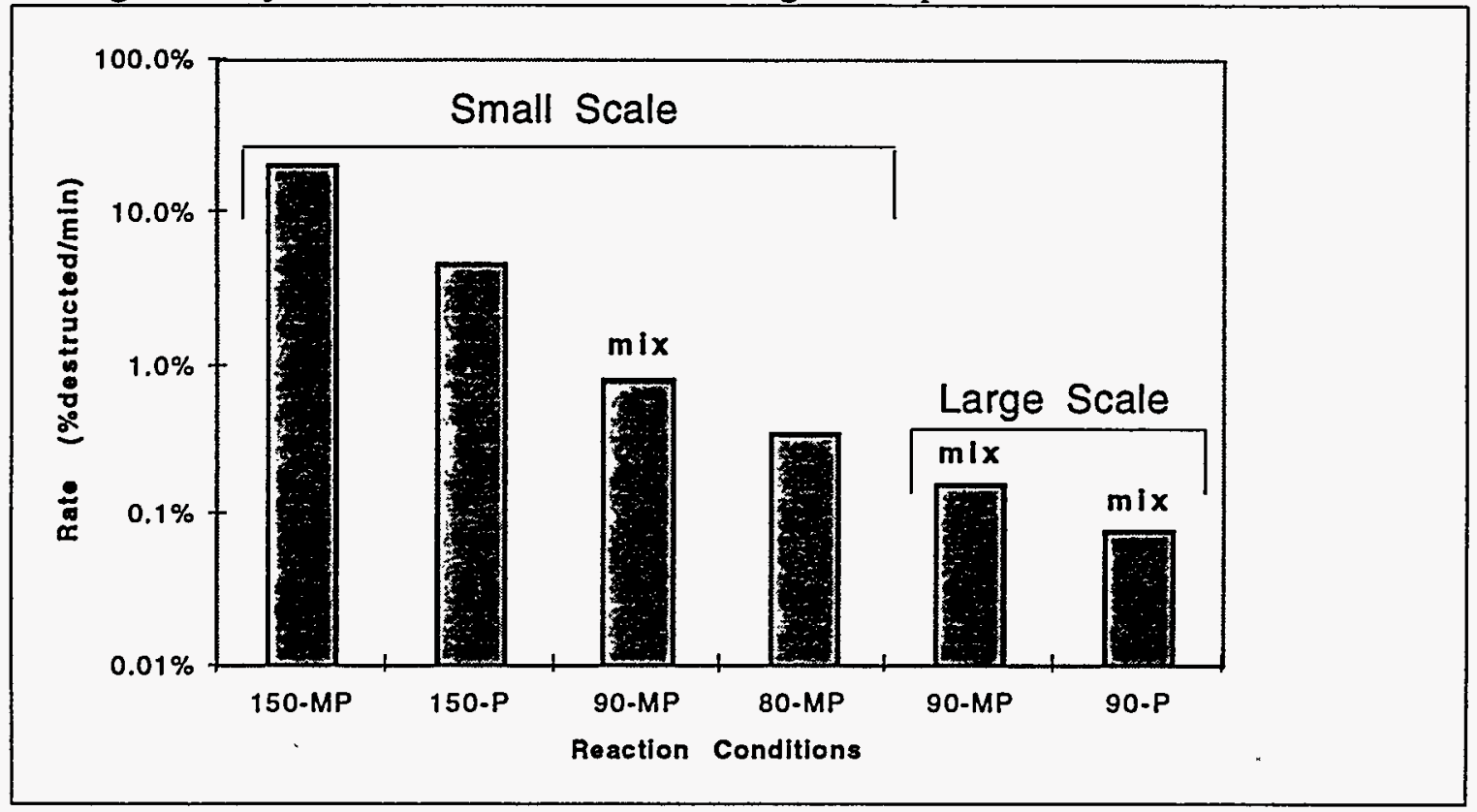

Figure 6. Reaction rate comparison between small and large scale reactions. Temperature $\left({ }^{\circ} \mathrm{C}\right)$ and explosive form are indicated on the $\mathrm{x}$-axis. MP refers to molding powder and $\mathrm{P}$ refers to consolidated pieces. Mixing was carried out in some experiments and is indicated.

\section{Product Analysis}

Major carbon products in solution consist of sodium formate and sodium acetate. These two products account for approximately 40 to $50 \%$ of the total carbon from the high explosive. Sodium nitrite is the major nitrogen product in solution accounting for approximately $20 \%$ of the nitrogen in the explosive. Gas data were not collected in these experiments. In previous experiments, ${ }^{6}$ nitrogen gas, nitrous oxide, and ammonia are released in the reaction, and account for about half of the nitrogen in the explosive. Total carbon and total organic carbon were also measured at the end of each experiment. These results are summarized in Table 2, which presents Ion Chromatography results for both sets of experiments. We are also aware that sodium glycolate is present in our product mixture, but glycolate and acetate elute out at similar retention times in our IC analysis.

The products shown in Table 2 are amenable to treatment by hydrothermal oxidation. Indeed, we have had success mineralizing organic carbon using nitrite and nitrate available in the solution. ${ }^{1}$ Hydrothermal oxidation experiments performed on PBX 9404 hydrolysate indicated that organic carbon conversions greater than $99 \%$ were achieved at relatively mild operating conditions $\left(374^{\circ} \mathrm{C}, 300 \mathrm{bar}\right)$. To completely mineralize the organic carbon, additional oxidant such as hydrogen peroxide must be added to the hydrothermal system. ${ }^{1}$ 


\begin{tabular}{|llll|}
\hline Table 2. Ion Chromatography Results for PBX & 404 pilot scale hydrolysis. & \\
\hline IC products (\% of C or N in explosive processed) & Molding & Consol. & Consol. \\
& powder 2 & piece 1 & piece 2 \\
\hline Acetate & $19 \%$ & $22 \%$ & $25 \%$ \\
Formate & $16 \%$ & $21 \%$ & $23 \%$ \\
Nitrite & $20 \%$ & $19 \%$ & $20 \%$ \\
Nitrate & $0.7 \%$ & $0.5 \%$ & $0.7 \%$ \\
Organic carbon & $99 \% *$ & $93 \%$ & $101 \%$ \\
Inorganic carbon & $1.1 \% *$ & $1.4 \%$ & $1.8 \%$ \\
\hline
\end{tabular}

* - Mass balances based on Total Carbon analytical results rather than amount of explosive left at end of experiment.

\section{Conclusions}

We have successfully hydrolyzed HMX plastic bonded pressed explosives at a pilot scales of less than $35 \mathrm{lb}$ of explosive. Reaction rates are slower than similar bench scale experiments due to decreases in mixing efficiency at larger scales. Times up to 20 hours are required to destroy $90 \%$ of the explosive. Major aqueous carbon products include sodium acetate, formate, and glycolate, all of which are amenable to hydrothermal oxidation. Lab scale experiments at higher temperatures (e.g., up to $150^{\circ} \mathrm{C}$ ) indicate that destruction rates may be an order of magnitude faster than reactions carried out at $90^{\circ} \mathrm{C}$. More work is needed to quantify scale-up data for these higher temperatures.

\section{Acknowledgments}

We would like to thank the DOE/DoD Memorandum of Understanding for funding this research.

\section{References}

1 Flesner, R.L., Dell'Orco, P.C., Spontarelli, T., Bishop, R.L., Kramer, J.F., Skidmore, C.B., Eaton, E. "Pressurized Alkaline Hydrolysis and Hydrothermal Oxidation of HMX based Energetic Materials as an Integrated Process for EM Disposal." Submitted to Proceedings of the JANNAF Propulsion and Subcommittee Joint Meetings, Tampa, Florida, (December 4-8, 1995).

${ }^{2}$ Heilmann, H.M., Strenstrom, M.K., Hesselmann, R.P.X., Wiesmann, U., Wat. Sci. Tech 30, 53 (1994).

${ }^{3}$ Cannizzo, L. F.; Mower, G. L.; Hunstman, L. R.; Achatz, W. R.; Edwards, W. W., J. Energ. Mater. 13, 331 (1995).

${ }^{4}$ Borcherding, R., "Treatment of Solid Propellant Manufacturing Wastes, Base Hydrolysis as an Alternative to Open Burning," Proceedings of the JANNAF Safety and Environment Protection and Propellant Development and Characterization Subcommittee Joint Meetings, San Diego, California, (July 13-14, 1995).

${ }^{5}$ Spontarelli, T., Buntain, G. A., Sanchez, J. A., Benzinger, T. M., "Destruction of Waste Energetic Materials Using Base Hydrolysis," Proceedings of the 12th (1993) Incineration Conference, Knoxville, Tennessee, (May 3rd-7th, 1993) p. 787.

${ }^{6}$ Flesner, R. L.; Spontarelli, T.; Dell'Orco, P. C.; Sanchez, J. A. "Base Hydrolysis and Hydrothermal Processing of PBX 9404" Accepted ACS Symposium Series, Emerging Technologies in Hazardous Waste Management VI. Sept. 19-21, (1994) Atlanta, GA. 


\section{Pilot-Scale Base Hydrolysis Processing of HMX-Based Plastic Bonded Explosives}

Ray Flesner, Phil Dell'Orco, Terry Spontarelli, Robert Bishop, Cary Skidmore, Kenneth Uher, John Kramer

4th International Symposium on Special Topics in Chemical Propulsion, Stockholm Sweden May 27-31, 1996

\section{Base Hydrolysis/Hydrothermal Processing Technology Summary}

Explosive

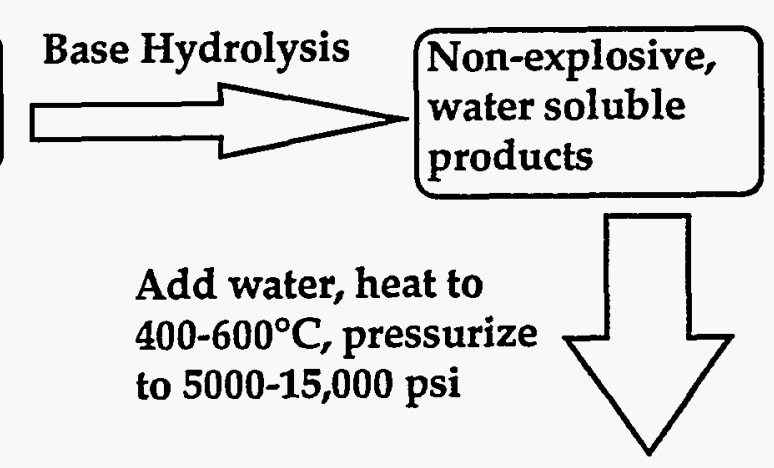

Products: $\mathrm{CO}_{2}$, $\mathrm{N}_{2}, \mathrm{~N}_{2} \mathrm{O}, \dot{\mathrm{H}}_{2} \mathrm{O}$ 


\section{Introduction, Base Hydrolysis}

- Reactions with $\mathrm{NaOH}$ or $\mathrm{NH}_{3}$ "de-energize" and solubilize many explosive materials

- Typical operating temperatures - 80 to $150^{\circ} \mathrm{C}$

- Base Hydrolysis Implementation:

- Large Rocket Motor Demil Program (General Atomics, Thiokol, Tyndall AFB)

- Eglin AFB (High Explosives Research and Development Facility)

- DOE (Pantex)

\section{PBX 9404 definition}

- DOE Explosive

- 94\% HMX, 3\% Nitrocellulose (binder), 3\% Tris (2-chloro ethyl) phosphate (plasticizer, $0.1 \%$ Diphenylamine (stabilizer for NC)

$\mathrm{HMX}$<smiles>O=[N+]([O-])C1CN([N+](=O)[O-])C[N+]([O-])([O-])CN([N+](=O)[O-])C1</smiles> 


\section{Lab Scale Base Hydrolysis}

- 2 Liter Parr reactor, $100 \mathrm{cc}$ reactor

- Temperatures up to $150^{\circ} \mathrm{C}$

- $\mathrm{NaOH}, \mathrm{NH}_{4} \mathrm{OH}, \mathrm{Na}_{2} \mathrm{CO}_{3}, 1-3 \mathrm{M}$

- Characterize rate of reaction

- Kinetics and/or mass transfer limitations

- Reaction mechanisms

- Product analysis

\section{Liter Parr Reactor}

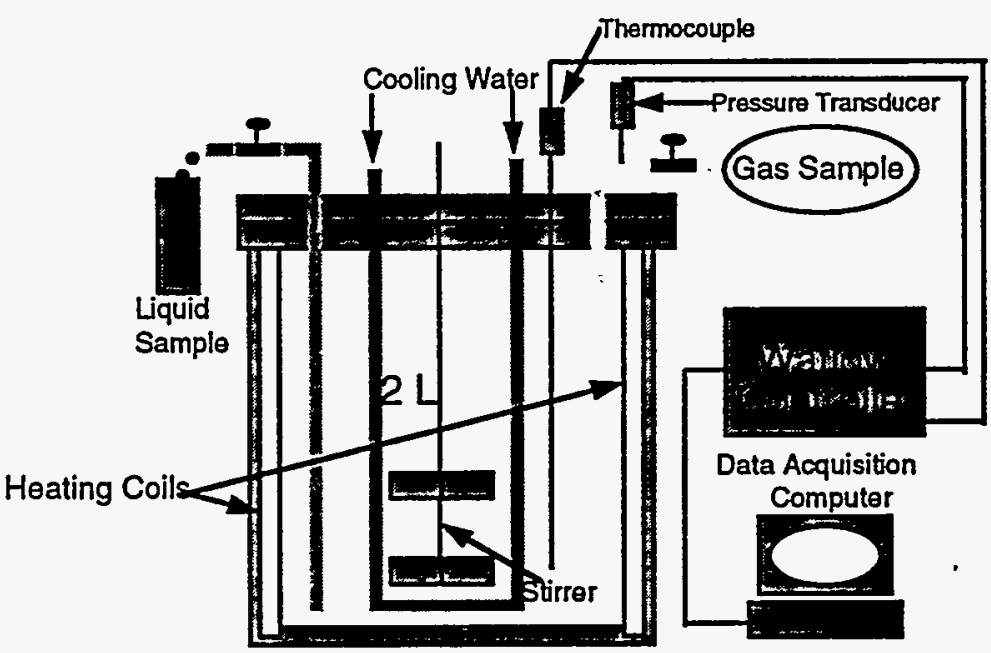




\section{PBX 9404 Pressure/Temp Profile}

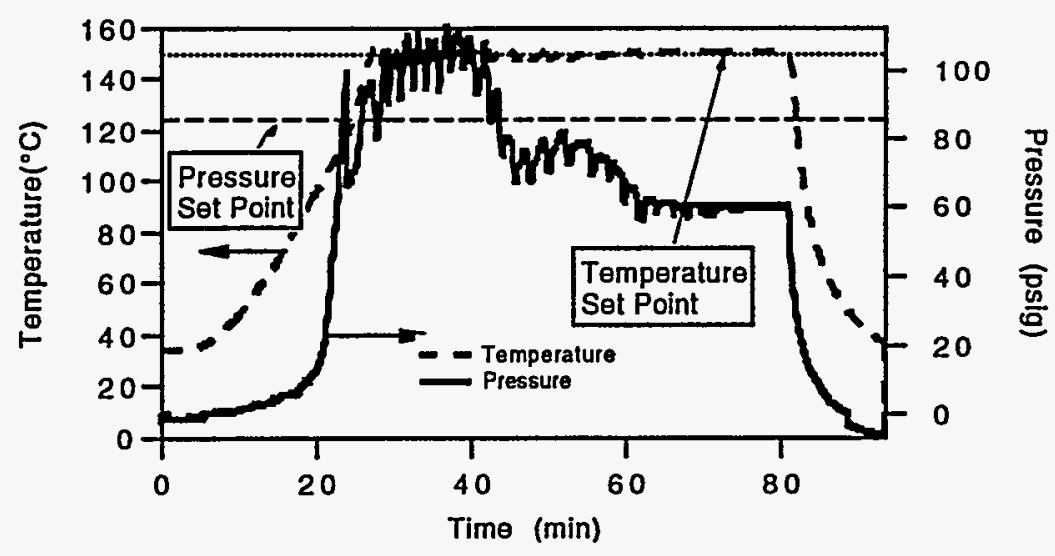

\section{Lab-Scale 9404 Experiments}

- Over 100 experiments performed on 9404 molding powder, pressed pieces, and HMX powder

- Bases used: $\mathrm{NaOH}, \mathrm{NH}_{4} \mathrm{OH}, \mathrm{Na}_{2} \mathrm{CO}_{3}$ at 1.5 $\mathrm{M}$ to $6 \mathrm{M}$

- 85 to $150^{\circ} \mathrm{C}, 14$ to $200 \mathrm{psi}, 1$ to 200 minutes time, diff't mixing intensities 


\section{Lab Scale 9404 Expts.: Rxn. Products}

- Aqueous Carbon Products: Acetate, Formate, Glycolate, Methylamine, Carbonate

- Aqueous Nitrogen Products: Nitrite, Nitrate, Ammonia, Methylamine

- Gas Products: $\mathrm{N}_{2} \mathrm{O}, \mathrm{N}_{2}, \mathrm{NH}_{3}$, Trace $\mathrm{CO}$

\section{Reaction Rate Comparison, Small and Large Scale}

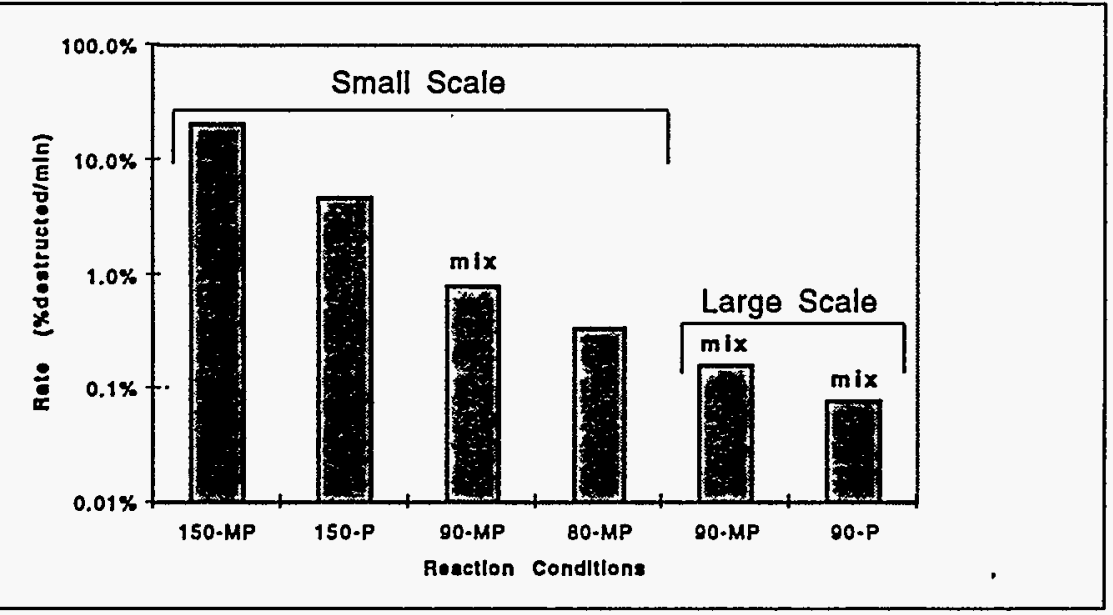

MP-refers to PQX 9404 molding powder

P-refers to consolidakd pieces

Numbers on $\mathrm{x}$-2xis are reaction lemperatures in ${ }^{\circ} \mathrm{C}$ 


\section{Base Hydrolysis: Mass Transfer and Kinetic Resistances}

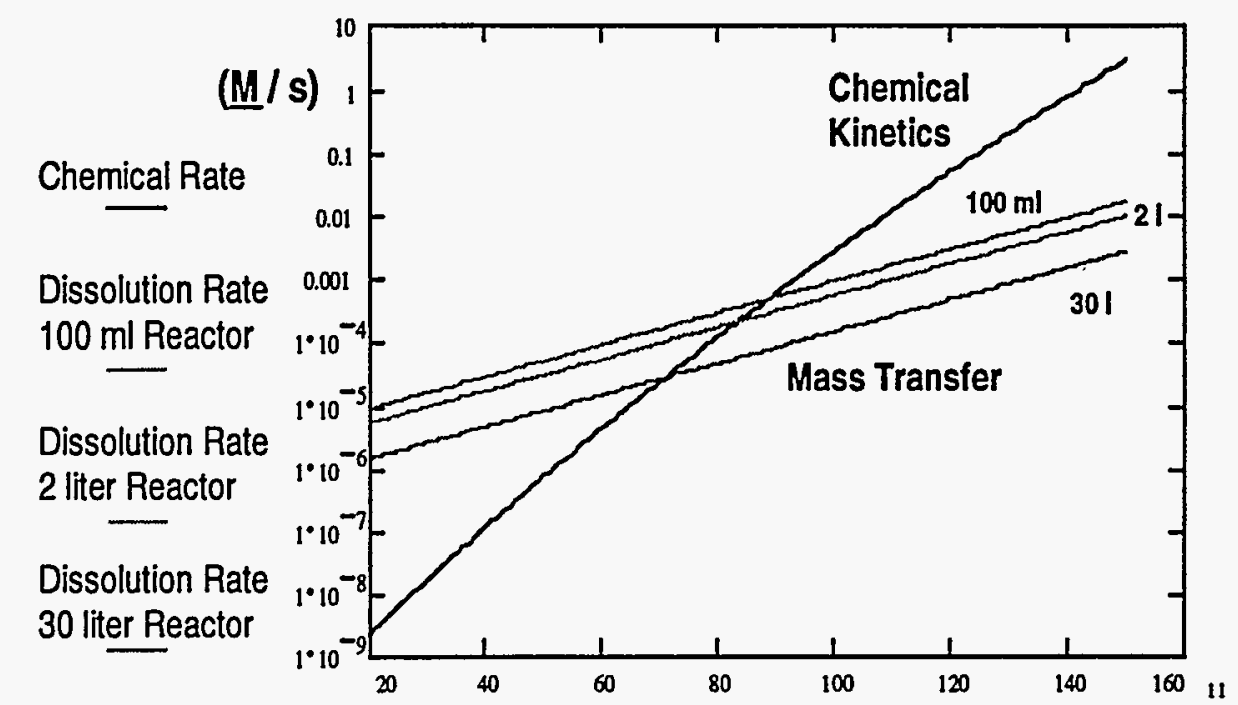

\section{DoD Explosives Studied}

- Octol (70\% HMX, 30\% TNT)

- Tritonal (80\% TNT, 20\% Al)

- Comp B-3 (60\% RDX, 40\% TNT)

- PBXN-109 (64\% RDX, 20\% Al, 16\% HTPB binder)

- Most pieces 1-2" dia, 1/2-3" height 


\section{Base Hydrolysis Scale-up}

- 55-gal base hydrolysis batch reactor

- Designed for consolidated pieces from DOE demil:

- atmospheric Pressure

- $\mathrm{NaOH}$ reactant

- Four large scale expts. carried out (PBX9404)

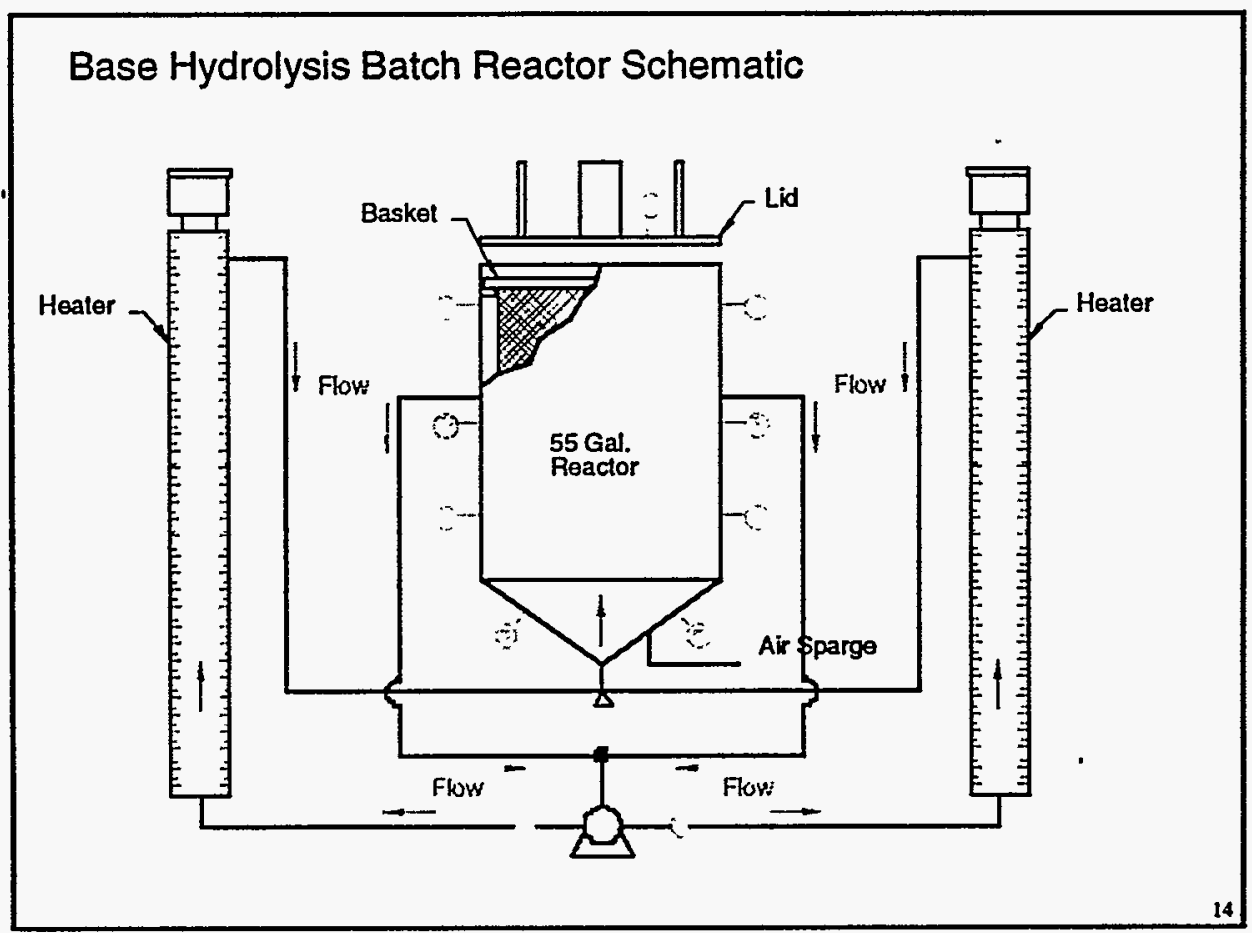




\section{LabVIEW Computer control panel for 55-gal reactor}

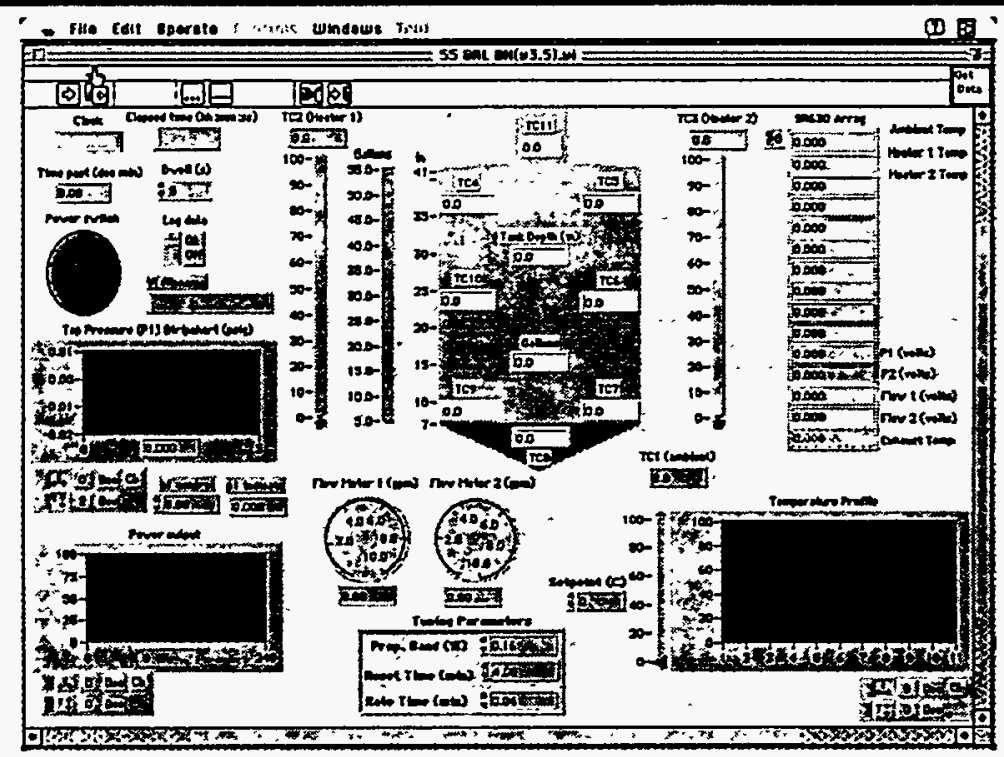

\section{Base Hydrolysis Scale-up (cont)}

- Two expts. with 30 lbs. PBX-9404 molding powder

- 1st expt. - plugging throughout reactor

» Reactor configuration could not handle HMX powder after binder degraded

- Flow design changed; 2nd expt. - no solids problems; $91 \%$ solids destruction in $<10$ hours 


\section{$30 \mathrm{lb}$ Molding Powder Expt.:}

\section{Temp. vs. Time}

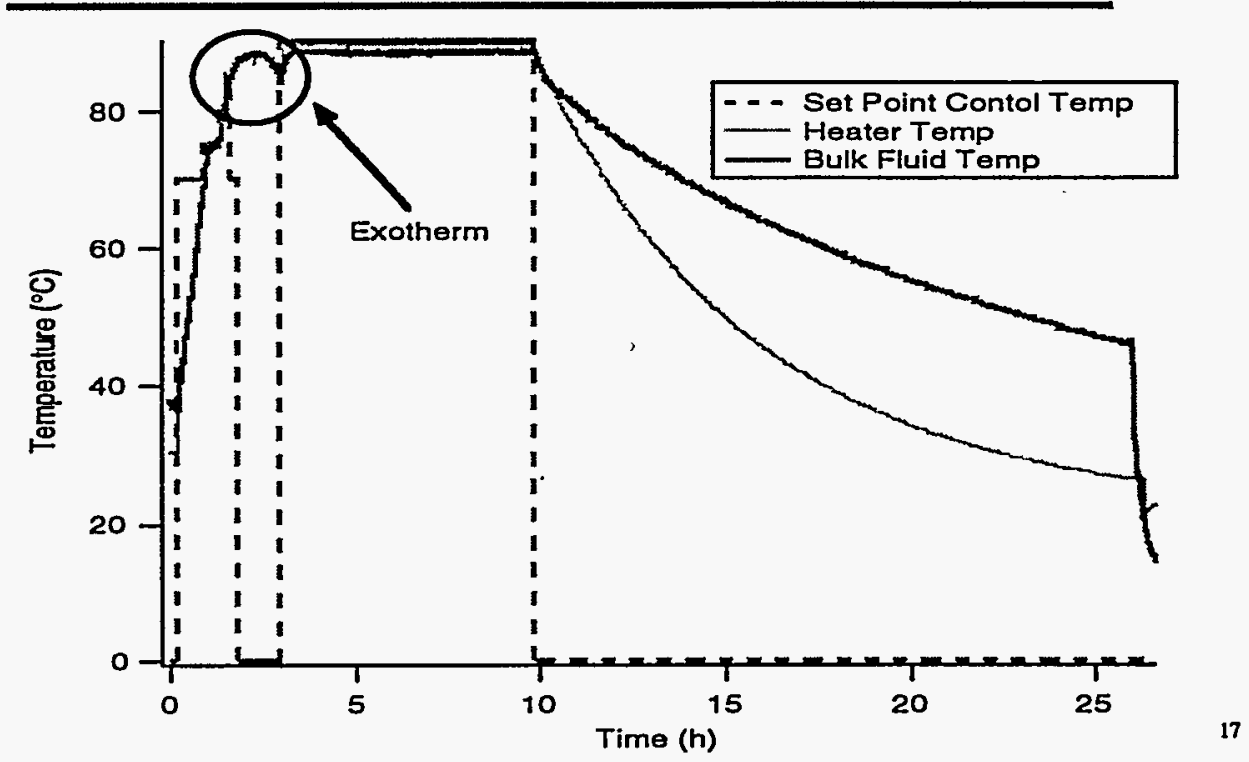

Base Hydrolysis Scale-up (cont)

- Two experiments with consolidated pieces in 55-gal reactor:

- 1st expt. - 94\% solids destruction after 21 hours at $80-90^{\circ} \mathrm{C}$

- 2nd expt. - $87 \%$ solids destruction after 18 hours at $80-90^{\circ} \mathrm{C}$

- Liquid phase products similar to products from bench expts. 


\section{Base Hydrolysis Economics}

- Overall cost, 500 metric tons /year:

- $\$ 1.50$ per pound for either atmospheric or pressurized process

- Cost breakdown:

$-10 \%$ capital

$-20 \%$ consumable

- $60 \%$ Labor

- 3\% Maintenance

$-7 \%$ Contingency

\section{Base Hydrolysis Future Work}

- Improve mixing in atmospheric Pressurized reactor

- Acquire 30 gal pressurized Reactor

- Process other DOE and DoD candidate explosives 


\section{Summary}

- Sodium hydroxide hydrolysis scaled from bench to small pilot scale for PBX 9404

- Consolidated energetic materials successfully processed

- Major reaction products determined

- Secondary treatment by hydrothermal oxidation:

- Lab scale kinetic studies completed

- Engineering scale-up in process

\section{Acknowledgments}

- DOE, Joint DoD/DOE Munitions Technology Program 


\section{Future Studies: Mass Transfer Coefficients}

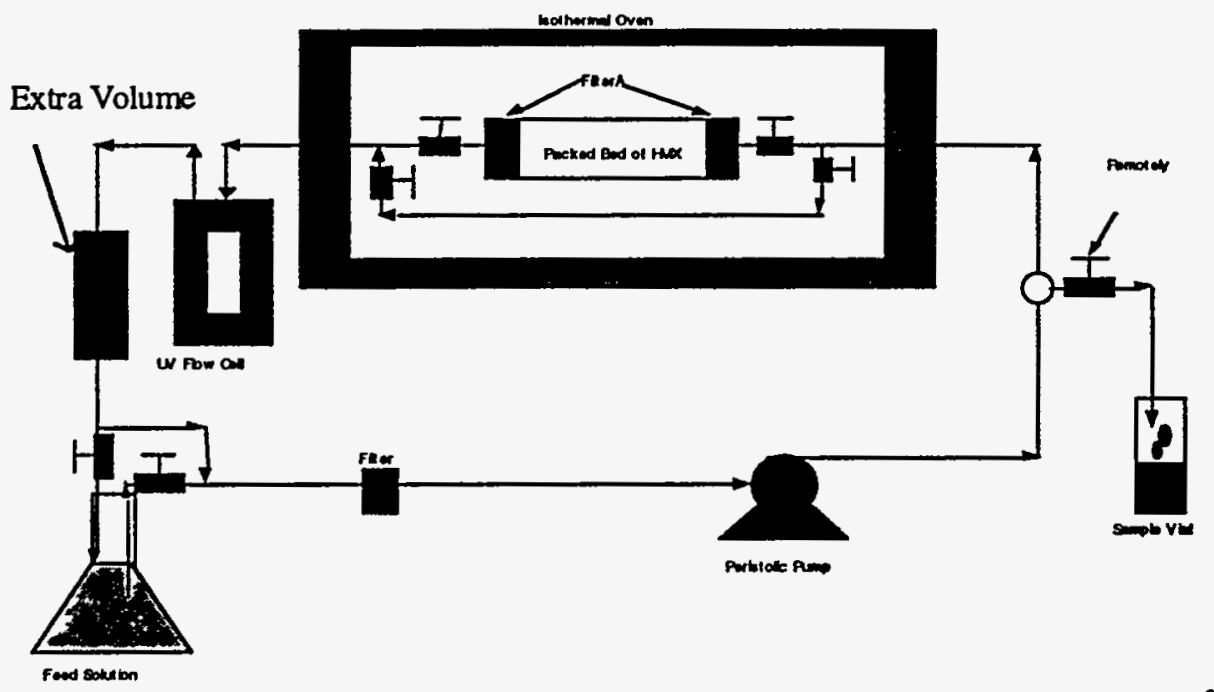

Batch reactor picture 


\section{PBX-9404 elevated pressure processing}

- Heated 2" Dia x 3" high cylinder to $150^{\circ} \mathrm{C}$ in $1.5 \mathrm{M} \mathrm{NaOH}$ for $53 \mathrm{~min}$ w/ no stirring

- Controllable exotherm

-99.8\% destruction 